\title{
ENABLING MOBILE COMMERCE THROUGH LOCATION BASED SERVICES
}

\author{
Yufei Wu, Ji Li, Samuel Pierre \\ Ecole Polytechnique de Montreal, Department of Computer Engineering \\ 5255 Decelles Building, Montreal \\ Canada \\ yufei.wu@polymtl.ca
}

\begin{abstract}
The use of mobile telecommunications devices for commercial transactions, called mobile commerce ( $m$-commerce), has been an emerging trend since the late 1990s. A killer application of m-commerce is Location Based Services (LBS). A host of new location-aware applications and services are emerging with significant implications for the future of $m$-commerce. The early stage infrastructure for enabling these services is just now reaching the commercialization stage. Strategic thinking in this area is rudimentary - there is not a clear understanding of issues associated with location services, such as business models. In this paper, we examine the technologies, applications, business models, and strategic issues associated with the commercialization of LBS, and give an outlook for future LBS development.
\end{abstract}

Keywords: Location Based Services, Mobile Commerce, Business Models

\section{Introduction}

Since the technological convergence of the Internet and mobile telecommunications networks in the 1990s, these technologies together have created the platform for a raft of mobile data services, including business-to-consumer (B2C) applications for financial services, gaming, email and news, and businessto-business (B2B) applications for tele-working, logistics, field sales and aftersales servicing. Worldwide, revenues from mobile ( $\mathrm{m}-$ ) commerce i.e., transactions over wireless telecommunications networks are expected to exceed 200 billion dollars by 2005 .

A new type of m-commerce represents the "killer" application: applications that take the user's location into account in order to deliver a service (VanderMeer, 2003). Examples of such "location-based services" (LBS) include those that identify nearby locations, such as when a cellular telephone user seeking information about restaurants is provided only the set of choices in the imme- 
diate vicinity. In the next stage of e-commerce and m-commerce development, location-based services (LBS) are expected to play an increasingly important role in helping to differentiate one service provider from another (Van de Kar et al., 2001). For this reason, this paper provides an overview of this emerging class of mobile services, examining the LBS market potential, its technological bases, the potential services, the industry value chain and likely business models, significant policy issues, and potential future directions.

\section{Location Based Services}

A wide range of services that rely on users' location information have been conceived, although the markets are not yet mature. The main point is to remember that location is simply a useful bit of data that can be used to filter access to many types of geo-graphical information services (GIS). There are numerous ways to exploit location to provide more relevant information, or derive new services. It can be particularly powerful when combined with other user profile to offer personalized and location sensitive responses to customers (Searby, 2003). Van de Kar et al., (2001) distinguishes between emergency services, mobile operator services, and value-added services (VAS), focusing on the latter category as the primary e-commerce opportunity.

Table 1. Location based service applications

\begin{tabular}{l|l}
\hline Location-Based Service & Application \\
\hline Information/directory services & $\begin{array}{l}\text { Dynamic yellow pages that automatically informs customer } \\
\text { of location of nearest parking facilities, restaurants, etc. } \\
\text { Travel, show, dinner reservations. Concierge services. }\end{array}$ \\
\hline Tracking services & $\begin{array}{l}\text { Tracking of children by parents. } \\
\text { Locating lost pets. } \\
\text { Locating friends in a geographic area. } \\
\text { Tracking stolen cars. } \\
\text { Tracking assets. }\end{array}$ \\
\hline Emergency services & $\begin{array}{l}\text { Roadside assistance. } \\
\text { Search and rescue missions. } \\
\text { Police and fire response. } \\
\text { Emergency medical ambulance. }\end{array}$ \\
\hline Navigation & $\begin{array}{l}\text { Route description. } \\
\text { Dynamic navigational guidance. } \\
\text { Traffic status in the area. }\end{array}$ \\
\hline Advertising promotions & $\begin{array}{l}\text { Wireless coupon presentation, targeted ads, and promotional } \\
\text { messages keyed to the location. } \\
\text { Promotional alert when a sale of a desired product takes place. } \\
\text { Customer identification in a store or a neighborhood. }\end{array}$ \\
\hline
\end{tabular}

In the VAS category, they describe a number of different service areas, including information, entertainment, communication, transaction, mobile office 
and business process support services. D'Roza et al., (2003) classify services into two broad categories: those that are requested by users once their location is determined, and those that are triggered automatically once a certain condition is met (e.g. a boundary is crossed). We might consider the former set to be "pull" services and the latter to "push" services. In addition, they also identify five groups of application areas: communication, fleet management, routing, safety and security, and entertainment. We can also classify services according to whether they apply to consumers, business customers, or employees in a firm. Some of the most commonly discussed services are briefly described in Table 1.

\section{Location Positioning Technologies}

One or more location methods can be used to determine the position of user equipment for LBS. It is also possible to distinguish between methods that are most useful inside and outside buildings. Leading candidates for indoor location identification include short-range radio, such as Bluetooth, and infrared (IR) sensors (Barnes, 2002). For example, developers could use Bluetooth or IR to build an automatic tour-guide system, such as for an art gallery; as the tourist with a suitably enabled PDA device moves into range of a piece of artwork, it could send out a signal that automatically displays information related to the artwork on the screen (Tseng et al., 2001). However, interesting though this is, the focus is on roaming, location-aware technology used largely outside buildings. For a detailed examination of the benefits and applications of short-range wireless technologies, see (Barnes, 2002).

Location techniques operate in two steps-signal measurements and location estimate computation based on the measurements which may be carried out by the user equipment or the telecommunications network. Subsequently, positioning techniques can be categorized into several varieties, each with its advantages and disadvantages. The main types are cell-location, advanced network-based, and satellite-based positioning. Three of the main categories of positioning methods are shown in Table 2 , in order of increasing accuracy.

\section{LBS Value Chain and Business Models}

There are different players that may be involved in bringing location-based services to the market. Among the parties involved are:

- Geographic information service (GIS) and other content providers who offer a range of mapping services and geographically oriented content, often accessed via a server known as a geoserver.

- Service providers who aggregate GIS and other content to create services. 
Table 2. Location based service applications

\begin{tabular}{l|l|l|l}
\hline Type & Methodology & Advantages & Disadvantages \\
\hline COO & $\begin{array}{l}\text { Network-based technology. } \\
\text { Base stations use RF signals } \\
\text { to track mobile devices. }\end{array}$ & $\begin{array}{l}\text { Relative widespread } \\
\text { infrastructure } \\
\text { No handset modification } \\
\text { required } \\
\text { Rapid implementation } \\
\text { and low cost. }\end{array}$ & $\begin{array}{l}\text { Hard to pin down } \\
\text { user's extract location } \\
\text { to a few meters }\end{array}$ \\
\hline GPS & $\begin{array}{l}\text { Handset-based technology. } \\
\text { Triangulation used to determine } \\
\text { exact location. }\end{array}$ & $\begin{array}{l}\text { Outdoor precision } \\
\text { within 5 meter range. } \\
\text { No dependent on the } \\
\text { network. }\end{array}$ & $\begin{array}{l}\text { Expensive. } \\
\text { User device must } \\
\text { be in direct line } \\
\text { of sight. } \\
\text { Device needs special } \\
\text { embedded chips }\end{array}$ \\
\hline WLP & $\begin{array}{l}\text { Positioning methods by using } \\
\text { UWB, RFID, WLAN etc. }\end{array}$ & $\begin{array}{l}\text { Positioning precision could } \\
\text { reach less than 1 meter. } \\
\text { No need for expensive } \\
\text { network infrastructure. } \\
\text { No need using mobile } \\
\text { operators' resources, } \\
\text { such as frequency. }\end{array}$ & \\
\hline
\end{tabular}

- Application vendors who package services for mobile operators.

- Location middleware providers who provide tools to facilitate mobile operators' use of various applications from different providers.

- Mobile operators who manage the infrastructure, collect the position data, offer the service to the end subscribers, and perform billing and collection services.

- Location infrastructure providers who sell the mobile location centers and other hardware and software to network operators.

- Handset manufacturers who sell devices capable of interacting with LBS.

Each of these parties stands to earn revenue from location based services, but the whole value chain requires standard data formats and interfaces to work effectively (Spinney, 2003). If each individual application has its own proprietary format, the costs to launch a suite of services for consumers would be prohibitive for mobile operators.

The business models for LBS will most likely vary considerably across services. Sources of revenue for service providers may include subscription fees for a bundle of service available via a portal, subscription fees for specific services, advertising, connection and airtime fees, fees for content, transaction fees or margins on the price of products ordered (D'Roza et al., 2003; Sadeh, 
2002). In some cases, such as for emergency 911 services, the operators may collect revenue to pay for the services through regular phone subscription fees. Another source of revenue may come from businesses that pay a fee in order to be included in location-based business directories, even if the service does not include any push-based advertising. Indeed, many privacy advocates have expressed opposition to the use of advertising that is pushed to the client, rather than specifically requested, suggesting that this is unlikely to be a viable revenue stream.

Most likely, LBS will use various combinations of revenue models. For example, customers may be offered the choice between advertiser and nonadvertiser supported services, with the former provided at no cost and the latter provided for a fee.

In addition, many location-based services will be offered as a business service to companies, targeting their employees. In these cases, the service will resemble something like a private network, with bulk or volume discounts offered to large business clients. Individual employees will not be charged. For firms, the motivation will be to enhance employee productivity and make particular business processes more efficient. Some analysts, in fact, believe that this will be the primary early market for location-based services.

\section{Commercialization Issues}

Mobile commercialization of location based services to increased revenues and profitability depends on how the different players in the value chain resolve the key strategic commercialization issues they are facing. These issues include the selection of the underlying location-aware technology, ownership of the location data, interoperability, and mitigating privacy concerns. We briefly highlight these issues in this section.

\section{Privacy}

Privacy handling is a major issue in LBS deployment and provision and a critical success factor to the wide acceptance of this technology framework. The terms privacy handling consolidate issues like ownership of location information, use of location information, disclosure to service providers, etc. Skepticism arises as to where and how privacy handling should take place within the LBS provision chain. Existing proposals from operators and standardization bodies specify a priority scheme whereby the core network elements (e.g., Home Location Registers) have master control on location information. The provision/disclosure of such information to other entities (e.g., location servers, LBS serving nodes, ASPs) is subject to subscriber needs (e.g., registration information) and regulatory frameworks. 


\section{Economic Control of Location Information}

In the value chain for the provision of location-based services, depending upon which method of determining location is used, service providers may be dependent upon cellular network operators for access to customers' location data. If the network operator had a competing location-based service, then they may have an incentive to either not make this information available, or to make it available on terms that place the competing service provider at a disadvantage. Policy makers will need to make clear exactly what the obligations are for the provision of location data, in addition to ensuring that I formed consent is enforced.

Analysts have also cautioned network operators to avoid the "walled garden" approach to location-based service provision. Operators might be lured by the opportunities for a larger share of the revenue if they provide their own restricted and branded set of services to users. Experience with WAP portals, and earlier generations of information services suggest that this strategy will fail. On the other hand, the fastest growth of wireless data services appears to be in Japan's iMode system, which does not restrict customers' access to third party services that are independent of the operator's brands (FCC, 2001). Imode also offers a full complement of location-based services known as i-area (Spinney, 2003).

\section{Quality of Service}

Operators have chosen different methods for determining location, and with varying costs and accuracy. Some location-based services may require more accuracy than others (Adusei et al., 2004). For example, driving directions may require an accuracy of 30 meters, while location-sensitive billing or mobile yellow pages may only need to locate a user within a range of 250 meters (Spinney, 2003). Moreover, if operators are using a GPS solution that requires a minute or more for the time to first fix, then such delays might result in quite inaccurate positioning in fast moving vehicles. Customers may not be able to obtain the requisite quality of service on a particular provider's network.

A more serious quality of service issue faces service providers who use the unlicensed spectrum. The introduction of wireless LANs in public settings, with fee-based access, creates an expectation for a certain quality of service. However, service providers might have little control over others' use of the same spectrum in that area, since it is unregulated and services might suffer from interference.

Another related issue is the extent to which location-based services will interoperate with different user terminal equipment. If a user roams, for example, to another state, region, or country, will their terminal equipment still be able to work with the available network infrastructures to determine location and pro- 
vide LBS? Manufacturers and operators are working together in the Location Interoperability Forum to help avoid fragmented supply of services.

\section{Interoperability}

We have seen previously that there is an almost bewildering variety of technologies, devices, networks and location-sensors, upon which location-based experiences might be developed. Our third major technical challenge is therefore interoperability. Interoperability of networks is a key issue, including roaming between different network providers and eventually exploiting multiple network technologies and/or architectures within a single experience, for example, simultaneously using cellular telephony to communicate with remote servers and peer-to-peer Bluetooth connections in order to communicate with other users nearby. Similarly, it makes sense to combine multiple locationsensing technologies so that they reinforce one another, an approach known as sensor fusion. Given that such heterogeneity is likely to be a feature of location-based experiences, it is important to develop suitably flexible middleware to support application developers in a 'pick-and-mix' approach to combining devices, networks and sensors.

\section{Future Directions}

It may seem a bit premature to discuss the future of the location-based service industry given its relative state of immaturity. Nonetheless, the extensive work in the computer science community on pervasive and context-aware computing further suggests that future systems will incorporate more than location information and data drawn from personal profiles in the provision of services. Rather, embedded sensors are likely to enrich the services with a wide range of additional context data. Additionally, the proliferation of unlicensed wireless and the rapidity with which both wireline and cellular operators have moved to integrate $802.11 \mathrm{~b}$ options into their portfolio of services suggests that convergence across between indoor and outdoor systems is likely to occur.

\section{Convergence Between Location Sensing Technologies}

As WiFi systems proliferate, it is possible that they may supply many LBS simply by virtue of being able to assume that connected parties are within range of a particular base station. This may threaten the viability of some services offered by mobile operators, since increasingly, WiFi hotspots are either free or very low in cost. On the other hand, seamless provision of location and context-aware services require a mix of technologies (Spinney, 2003; Unni et al., 2003). A consumer may initiate a request from his or her car for all businesses in the local area using a GPS equipped PDA or cellular phone. The service provider may provide navigational services to direct the consumer to 
the appropriate location. Upon entering the business, a local WiFi network may provide additional information, and guide the consumer to their desired product. Some method for handover of such applications is needed, without requiring consumer to re-input product preferences. Spinney (2003) discusses handover methods that rely on both the location of the mobile phone user and the location of the indoor "hotspot." He further sees future handsets incorporating both cellular and 802.11 capabilities. These connections need to be seamless and without effort, especially if users are paying for access to services.

Many applications lose their value if customers, or business users are out of reach once they enter indoor environments. For this reason, we may see greater efforts to integrate applications across the variety of technologies for location-based services.

\section{Context Awareness}

Up to now, most service providers are focusing their attention on location as the primary type of information to use when customizing services for subscribers. However, researchers active in the area of mobile computing consider location to be only one aspect of a users' context. Over the past decade, computer scientists have been exploring a variety of ways to make computerbased applications sensitive to location as well as other contextual information (Hightower et al., 2001; Schmidt et al., 1999). Context may include both user provided profile information, as well as other aspects of context that may be detected by the system.

Some of the research on context-aware computing has quite direct implications for e-commerce. First, much of the research has been completed in indoor environments, using such location and context detection technologies as infrared, ultrasound, and low power radio (Schmidt et al., 1999). Hence, it has the potential to fill in an important gap in the coverage afforded by GPS and some public cellular network-based location services. Unlike straight wireless LANs, which generally do not determine the location within a building or room, these systems do provide precise positioning indoors. Retailers, for example, may be interested in helping shoppers find products once they are already inside malls or stores, and providing highly local navigation aides (Schmidt et al., 1999). Depending upon the granularity of the position detection, as well as user preference information, changing information could be provided to PDAs as shoppers moved about a store or mall. Such systems have obvious application in museums and other tourist areas.

Other types of context information may come from sensors deployed on machines. Automotive firms talk about "telematic services" as including data about the state of particular components on vehicles, such as their need for 
repair. This information can be sent from vehicles to car dealers, setting up preventative maintenance appointments prior to breakdowns.

\section{Concluding Remarks}

Our overview of location-based services reveals that the market potential is thought to be significant, driven in part by the deployment of automatic location identification systems for emergency response. There are, however, significant barriers to overcome. Technological barriers result from the diversity and cost of approaches to location determination, creating a complex set of choices for operators and potential interoperability problems that, if unsolved, are likely to stifle development. There are many exciting services under development, and some have been operating successfully in such markets as Japan for several years. Innovative applications such as location-based games have achieved a following in Sweden and been introduced into other markets. Despite the promise of LBS for consumers, however, privacy concerns, quality of service problems, fair access to location information, and the lack of standards for technology and service providers may hinder market development and represent critical policy issues to be resolved. Finally, in the area of potential future directions, it is evident that location is merely a starting point for personalization and context-aware services that use other relevant information when constructing service offers. Moreover, the rapid deployment of alternative wireless technologies, such as Wireless Fidelity (WiFi or 802.11) is both a threat and an opportunity for cellular operators, and will likely shape the future development of LBS.

\section{References}

Adusei, I. K, Kyamakya, K., Erbas, F., 2004, Location-based services : Advances and Challenges. $C C E C E$.

Barnes, S.J., 2002, Under the skin: Short-range embedded wireless technologies, International Journal of Information Management, 22(3): 165-179.

D'Roza, T., Bilchev, G., 2003, An overview of location based services, BT Technology Journal 21(1): 20-27.

Hightower, J., Borriello, G., 2001, Location systems for ubiquitous computing, IEEE Computer, 8: $57-66$

Sadeh, H, 2002, M-Commerce: Technologies, Services, and Business Models, Wiley, New York.

Schmidt,A., Beigl, M., Gellersen, H., 1999, There is more to context than location, Computers and Graphics Journal 23(6): 893-902

Searby, J., 2003, Personalization- An overview of its use and potential., BT Technology Journal 21(1): 13-19.

Spinney, J., 2003, A brief history of LBS and how OpenLS fits into the new value chain. Java Location Services Newsletter.

Tseng, Y.C., Wu, S. L., Liao, W. H., Chao, C. M., 2001, Location awareness in ad hoc wireless mobile networks, IEEE Computer 34(6): 46-52. 
Unni, R., Harmon, R., 2003, Location-based services:Models for strategy development in mMCommerce. Proceedings of PICMET-2003, Portland International Conference on Management of Engineering and Technology, Portland, $\mathrm{OR}$.

Van de Kar, E., Vetter, R. (October 2001), The development of location based mobile services, Edispuut Conference, Amsterdam.

VanderMeer J., (March/April, 2003), What is the difference between M-Commerce and LCommerce, Business Geographics. 